\title{
Restriction of dietary protein decreases mTORC1 in tumors and somatic tissues of a tumor-bearing mouse xenograft model
}

\author{
Dudley W. Lamming ${ }^{1,2,3, *}$, Nicole E. Cummings ${ }^{1,2,3}$, Antonella L. Rastelli ${ }^{4}$, \\ Feng Gao ${ }^{5}$, Edda Cava ${ }^{6,7}$, Beatrice Bertozzi ${ }^{6}$, Francesco Spelta ${ }^{6,8}$, Roberto Pili ${ }^{9}$, \\ Luigi Fontana $6,10,11, *$ \\ ${ }^{1}$ Department of Medicine, University of Wisconsin-Madison, Madison, WI, USA \\ ${ }^{2}$ William S. Middleton Memorial Veterans Hospital, Madison, WI, USA \\ ${ }^{3}$ Endocrinology and Reproductive Physiology Graduate Training Program, University of Wisconsin-Madison, Madison, WI, USA \\ ${ }^{4}$ Division of Oncology, Washington University in St. Louis, MO, USA \\ ${ }^{5}$ Division of Biostatistics, Washington University in St. Louis, MO, USA \\ ${ }^{6}$ Division of Geriatrics and Nutritional Sciences, Washington University in St. Louis, MO, USA \\ ${ }^{7}$ Department of Experimental Medicine, University of Rome "La Sapienza", Italy \\ ${ }^{8}$ Department of Medicine, University of Verona, Italy \\ ${ }^{9}$ Division of Hematology/Oncology, Department of Medicine, Indiana University School of Medicine, Indianapolis, IN, USA \\ ${ }^{10}$ Department of Clinical and Experimental Sciences, Brescia University Medical School, Brescia, Italy \\ ${ }^{11}$ CEINGE Biotecnologie Avanzate, Napoli, Italy \\ * These authors have contributed equally to this work \\ Correspondence to: \\ Luigi Fontana, e-mail: fontana.luigi@gmail.com \\ Dudley W. Lamming, e-mail: dlamming@medicine.wisc.edu
}

Keywords: protein restriction, mTOR, mice, cancer, aging

Received: June 21, 2015

Accepted: August 20, 2015

Published: September 03, 2015

\section{ABSTRACT}

Reduced dietary protein intake and intermittent fasting (IF) are both linked to healthy longevity in rodents, and are effective in inhibiting cancer growth. The molecular mechanisms underlying the beneficial effects of chronic protein restriction (PR) and IF are unclear, but may be mediated in part by a downregulation of the IGF/mTOR pathway. In this study we compared the effects of PR and IF on tumor growth in a xenograft mouse model of breast cancer. We also investigated the effects of PR and IF on the mechanistic Target Of Rapamycin ( $m$ TOR) pathway, inhibition of which extends lifespan in model organisms including mice. The mTOR protein kinase is found in two distinct complexes, of which mTOR complex 1 ( $m$ TORC1) is responsive to acute treatment with amino acids in cell culture and in vivo. We found that both PR and IF inhibit tumor growth and mTORC1 phosphorylation in tumor xenografts. In somatic tissues, we found that PR, but not IF, selectively inhibits the activity of the amino acid sensitive mTORC1, while the activity of the second $m$ TOR complex, $\mathrm{mTORC2}$, was relatively unaffected by PR. In contrast, IF resulted in increased $\mathbf{S 6}$ phosphorylation in multiple metabolic tissues. Our work represents the first finding that PR may reduce mTORC1 activity in tumors and multiple somatic tissues, and suggest that PR may represent a highly translatable option for the treatment not only of cancer, but also other agerelated diseases. 


\section{INTRODUCTION}

Chronic restriction of dietary protein intake and intermittent fasting are both strongly associated with health and longevity in rodents [1-4]. Epidemiological data suggest high protein intake is associated with a $75 \%$ increase in overall mortality in humans, as well as a 4-fold increase in cancer death $[1,5]$. Protein restriction (PR) and intermittent fasting (IF) regimens also show beneficial effects on rodent models of age-related diseases, including cancer and Alzheimer's disease [6-8]. However, the molecular mechanisms underlying the beneficial effect of PR and IF diets on metabolic health and longevity have not been clearly established, although PR and IF diets significantly reduce circulating levels of IGF-1 (Insulinlike growth factor 1), a potent activator of the mTOR (mechanistic Target Of Rapamycin) signaling pathway $[9,10]$.

Inhibition of the insulin/IGF-1/PI3K/mTOR signaling pathway either genetically or by treatment with the FDA-approved pharmaceutical rapamycin promotes longevity and inhibits tumor growth in model organisms [7, 11-14]. Unfortunately, the potentially serious side effects of rapamycin and rapamycin analogs in humans may preclude the use of these compounds to prevent or delay age-related diseases $[15,16]$. The mTOR protein kinase is found in two complexes, mTOR complex 1 (mTORC1) and mTORC2, each with distinct substrates; genetic studies have demonstrated that inhibition of mTORC1 signaling is sufficient to extend lifespan, while inhibition of $\mathrm{mTORC} 2$ reduces insulin sensitivity and decreases male lifespan [17]. We and others have demonstrated that chronic treatment of mice with rapamycin results in the disruption of both mTOR complexes $[18,19]$. Disruption of mTORC2 contributes to the negative metabolic and immunological side-effects of rapamycin, and we have proposed that specifically inhibiting mTORC1 would promote longevity and prevent age-associated diseases (e.g. cancer) with many fewer side effects than rapamycin, which inhibits both complexes [16].

In this study we compared the effects of chronic or intermittent reduction of protein intake on tumor growth in a xenograft mouse model of breast cancer. As amino acid levels in serum and tissue are regulated by dietary protein intake [20], and mTORC1 is acutely sensitive to amino acids, which activate mTORC1 by promoting its localization to the lysosome and its interaction with Rheb, we also examined mTORC1 and mTORC2 signaling not only in the xenograft tumors but also in several key metabolic tissues (liver, skeletal muscle, heart muscle and adipose tissue) of mice fed either a $21 \%$ and $7 \%$ protein diet ad libitum, or maintained on an IF regimen utilizing either a $21 \%$ or $7 \%$ protein diet.

\section{RESULTS}

\section{Protein restriction and intermittent fasting inhibit tumor growth in a human breast cancer model}

To test the hypothesis that chronic dietary PR was more effective than intermittent fasting (IF) in inhibiting tumor growth in an animal model of human breast cancer, we acclimatized 4-6 week old female NOD-SCID mice to either a $21 \%$ or $7 \%$ (PR) protein diet, fed ad libitum or intermittently (IF) for 4 weeks, prior to subcutaneous implantation of WHIM16 ER+/PR-/HER2- tumor cells. Mice fed a PR diet either ad libitum or intermittently were approximately $10-15 \%$ lighter than mice fed a control diet by the latter half of the study, while mice fed a $21 \%$ diet intermittently were the same weight as ad libitum fed mice (Fig. 1A). As we have previously shown [7], the growth of WHIM16 ER+/PR-/HER2- xenografts is significantly reduced in mice fed a $7 \%$ protein diet ad libitum compared to a $21 \%$ protein control diet (Fig. 1B). Interestingly, we find that IF has similar effects, independent of dietary protein intake, in reducing tumor growth. The tumor growth rate in mice fed either diet intermittently (every other day) was significantly smaller than that in mice on an ad libitum $21 \%$ protein diet (Fig. 1C). The tumor volume of IF mice was significantly lower than of mice fed either a $21 \%$ or a $7 \%$ protein diet ad libitum during the second part of the study (Fig. 1B).

\section{Protein restriction attenuates mTOR activity in human breast cancer xenografts}

The mTOR signaling pathway is a critical regulator of growth and cellular proliferation, and mutations that activate mTORC1 are linked to cancer [21-23]. mTORC1 activity is highly responsive to amino acids, which are significantly reduced in mice on a PR diet $[24,25]$, and mTORC1 is significantly reduced on a protein-free diet [20]. We were therefore interested in determining whether or not a $2 / 3$ rds reduction in protein intake down-regulates the mTORC1 signaling pathway in a mouse model of human breast cancer, and whether this effect was stronger than intermittent fasting, in which proteins are reduced intermittently. To test this hypothesis, we assessed the phosphorylation of S6 S240/S244, a substrate of S6K1 and a readout for mTORC1 activity. We also assessed the phosphorylation of AKT S473, a substrate of the amino acid insensitive mTORC2.

As shown in Fig. 2, tumors from mice fed a PR diet ad libitum or mice subject to intermittent fasting of a $21 \%$ protein diet had an over $30 \%$ decrease in phosphorylated S6, indicating decreased mTORC1 activity (Fig. 2A, 2B). Interestingly, while mice 
A)

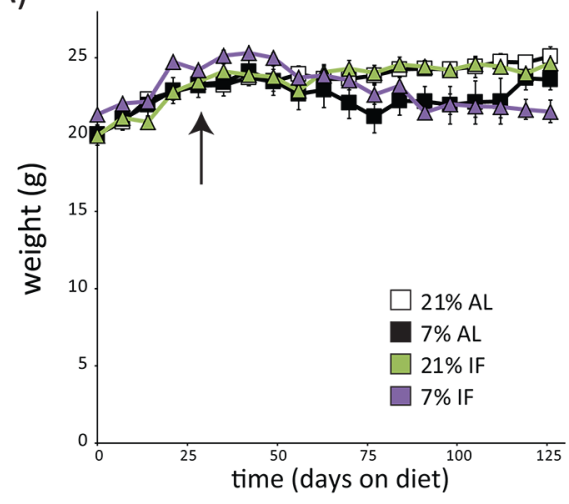

B)

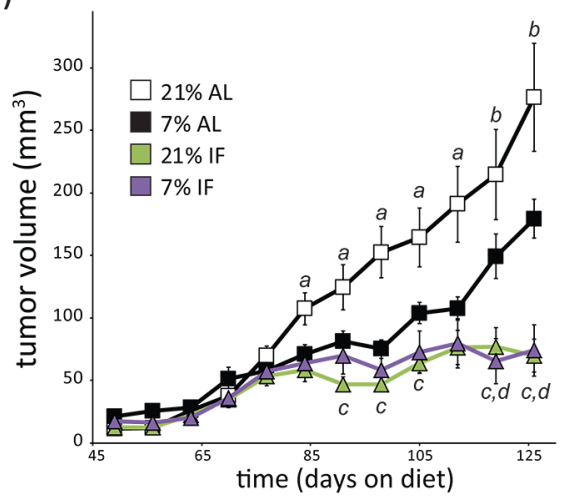

C)

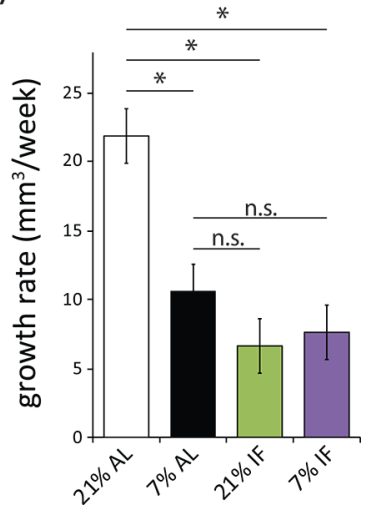

Figure 1: A low protein diet or intermittent fasting regimen slows tumor growth rate in a mouse model of breast cancer. A. Weights of 6 week old female mice placed on diets containing either $21 \%$ or $7 \%$ protein, which were fed either ad libitum (AL) or with intermittent, alternate day fasting (IF). Arrow indicates time of tumor implantation on day 29. B. Tumor volumes were measured weekly starting 20 days after tumor cell implantation. ( $n=7-10$ mice per group, $a=p \leq 0.05, b=p \leq 0.09,21 \%$ AL vs. all other groups; $c=p<0.008,7 \%$ AL vs. $21 \%$ IF; $d=p<0.006,7 \%$ AL vs $7 \%$ IF). Data in A-B for AL fed mice was previously published in part [7] and is shown here for comparison. C. Growth rates of tumors in mice on each indicated diet was calculated using the method of Laird and Ware [34] from tumor volumes measured 3-12 weeks after tumor implantation $(n=9-10$ mice per group, $p<0.0001)$.

intermittently fasted with a PR diet had normal levels of S6 phosphorylation (Fig. 2B), the expression of S6 itself was significantly reduced (Fig. 2C). Biogenesis of ribosomal proteins like $\mathrm{S} 6$ is itself mediated by mTORC1 [26, 27], suggesting that mTORC1 activity was decreased in these tumors as well. We determined that the abundance of phosphorylated S6 in the tumors of mice intermittently fasted with a PR diet relative to control, ad libitum mice was decreased by $44 \%(p=0.002)$. In agreement with our hypothesis that reduced protein intake would specifically reduce mTORC1 activity, phosphorylation of AKT S473 was not affected by PR; however, intermittent fasting significantly decreased AKT phosphorylation (Fig. 2B).

\section{A low protein diet inhibits mTORC1 but not mTORC2 signaling in somatic tissues}

We collected liver, skeletal muscle, heart, and adipose tissues at the end of the tumor xenograft study, and examined tissue lysates by Western blotting to test the systemic effects of protein restriction and intermittent fasting on other key metabolic tissues. We observed a dramatic effect of a PR diet on mTORC1 signaling in somatic tissues, including a greater than $60 \%$ decrease in S6 phosphorylation in liver $(p=0.007)$ and skeletal muscle $(p=0.0067)$, and a $50 \%$ decrease in heart tissue $(p=0.0172)$ (Fig. 3A-3C). We also observed a 30\% decrease in $\mathrm{S} 6$ phosphorylation in adipose tissue, but it was not significant after correction for multiple comparisons $(p=0.5)$ (Fig. 3D). In contrast, tissues from mice subject to intermittent fasting on the $21 \%$ diet showed a significant increase of S6 phosphorylation in liver and adipose tissue, as well as a $48 \%$ increase $(p=0.058)$ in skeletal muscle (Fig. 3). Mice intermittently fasted on the 7\% diet displayed increased S6 phosphorylation in heart and adipose tissue (Fig. 3). In contrast to mTORC1 activity, there was no effect of a PR diet on mTORC2 signaling as assessed by AKT S473 phosphorylation in any tissue (Fig. 3A-3D). However, intermittent fasting increased AKT S473 phosphorylation in the heart, regardless of diet composition, with a similar increase in AKT phosphorylation in $21 \%$ IF muscle and $7 \%$ IF adipose tissue.

\section{DISCUSSION}

Diets with chronic restriction of protein intake and intermittent fasting have been demonstrated to extend lifespan and inhibit age-related diseases such as cancer. Here, we compare the effect of dietary composition and intermittent fasting on cancer growth and mTOR pathway signaling. We have found that both a reduction in dietary protein and intermittent fasting slow tumor growth rate, but have distinguishable effects on mTOR signaling both in the tumor and the somatic tissues of a tumor-bearing mouse. Within the tumor, we determined that ad libitum feeding of a 7\% protein diet or intermittent fasting of a $21 \%$ protein diet significantly inhibits mTORC1 signaling. Previous studies have suggested that rapamycin-resistant functions of mTORC1 contribute to cell growth and cancer progression [28], and thus it will be interesting to determine if reduced dietary protein intake inhibits both rapamycin dependent and independent functions of mTORC1.

Unlike reduced dietary protein intake, we found that intermittent feeding inhibits mTORC2 as well 
A)

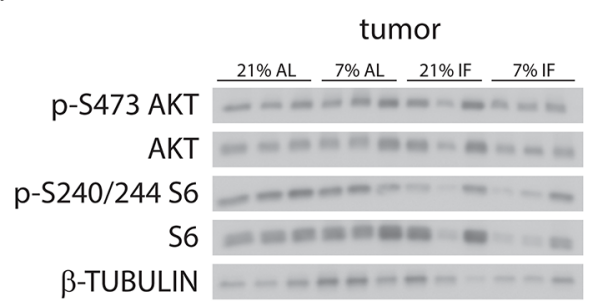

B)

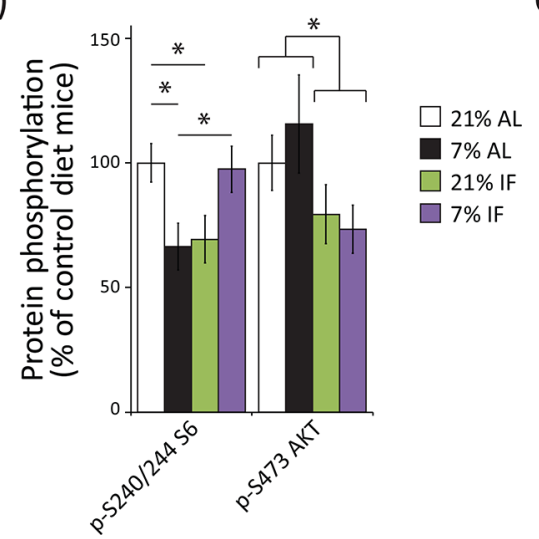

C)

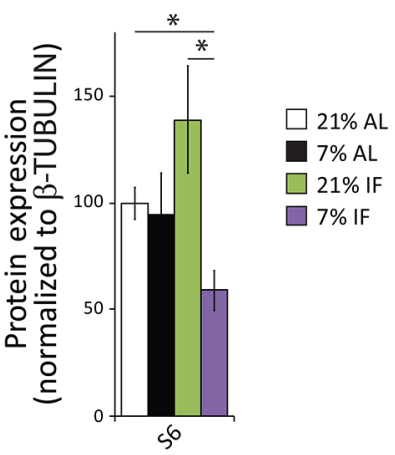

Figure 2: A protein restricted diet inhibits mTORC1 signaling in tumors. A. Tissue lysates from tumor xenografts were examined for phosphorylation of S6 S240/S244 and AKT S473 by western blotting. B. Quantification of S6 and AKT phosphorylation, normalized to total S6 or AKT protein, was performed using NIH ImageJ. C. Quantification of S6, normalized to $\beta$-TUBULIN, was performed using NIH Image J ( $n=7-10$ tumors per group, $*=p<0.05 t$-test following ANOVA).

A)

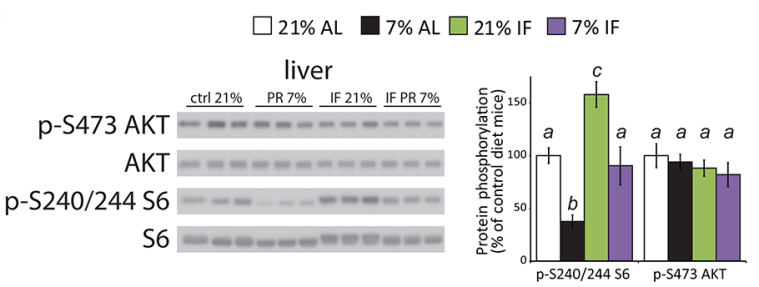

C)

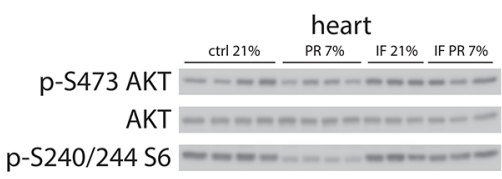

S6

$\square 21 \% \mathrm{AL} \quad \square$ 7\% AL $\square 21 \% \mathrm{IF} \square 7 \% \mathrm{IF}$

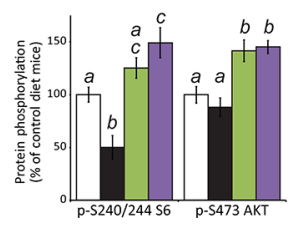

B)

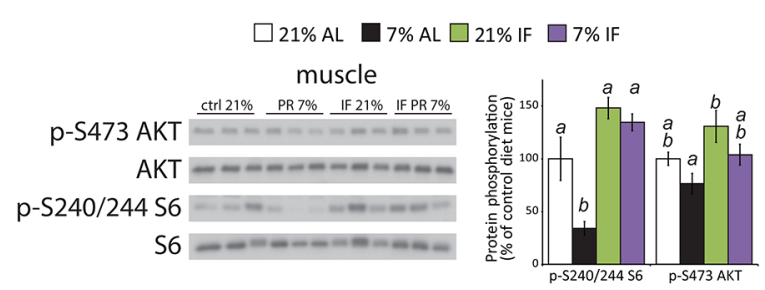

D)

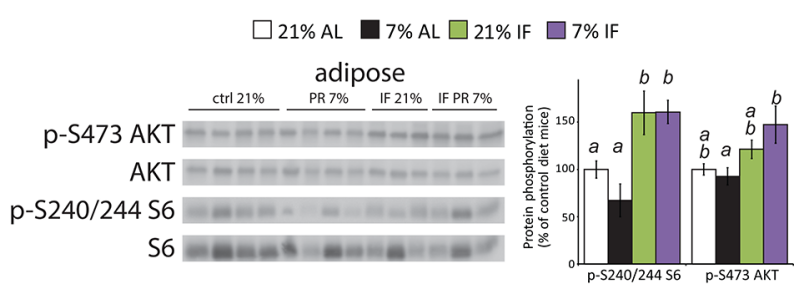

Figure 3: A protein restricted diet inhibits mTORC1 signaling in vivo. Tissue lysates from A. liver, B. muscle, C. heart and D. adipose tissue were examined for phosphorylation of S6 S240/S244 and AKT S473 by western blotting. Quantification of S6 and AKT phosphorylation, normalized to total S6 or AKT protein, was performed using NIH ImageJ ( $n=6-7$ samples per group, means with the same letter are not significantly different from each other (Tukey-Kramer test following ANOVA, $p<0.05$ )).

as mTORC1. Inhibition of mTORC2 inhibits cancer progression in at least some cancers [29, 30], and thus intermittent fasting may be a particularly potent anticancer therapy. It is potentially important that we sacrificed the intermittently fasted mice following a day on which they enjoyed access to food; mTOR signaling in intermittently fasted mice following a fasting day might look quite different (e.g., mTORC1 signaling might be significantly decreased relative to ad libitum fed mice). It remains to be determined if additional, mTORindependent mechanisms may also contribute to the anticancer effects of PR and IF dietary regimens.
Within the somatic tissue of the mouse, we have demonstrated that a simple dietary intervention, reduction of dietary protein intake by $2 / 3 \mathrm{rds}$, is sufficient to significantly inhibit mTORC1 signaling in the liver, muscle, and heart tissues of NOD.Cg-Prkd csid $I l 2 \mathrm{rg}^{\mathrm{tm} I \mathrm{~W}_{j} l}$ / SzJ mice. Importantly, this occurs in the absence of mTORC2 inhibition, which is responsible for many of the negative side effects of rapamycin on metabolism and immunity [16, 17, 31-33]. Protein restriction may therefore be a highly translatable intervention for agerelated diseases in humans, and the $2 / 3$ rds reduction in dietary protein we have utilized here is likely to be far 
Table 1: Calculated composition and ingredients of experimental diets used

$21 \%$ mix protein TD.10193

7\% mix protein TD.10192

\begin{tabular}{|c|c|c|}
\hline Diet composition & & \\
\hline Total energy value (kcal/g) & 3.6 & 3.6 \\
\hline Carbohydrate (\%Kcal) & 58.9 & 73.0 \\
\hline Fat $(\% \mathrm{kcal})$ & 20.1 & 20.2 \\
\hline Protein $(\% \mathrm{Kcal})$ & 20.9 & 6.8 \\
\hline Leucine $(\mathrm{g} / \mathrm{kg})$ & 25.4 & 8.8 \\
\hline Isoleucine $(\mathrm{g} / \mathrm{kg})$ & 7.8 & 2.7 \\
\hline Lysine (g/kg) & 16.3 & 4.0 \\
\hline Methionine $(\mathrm{g} / \mathrm{kg})$ & 6.7 & 1.9 \\
\hline Cysteine (g/kg) & 7.2 & 3 \\
\hline Arginine $(\mathrm{g} / \mathrm{kg})$ & 6.3 & 2.9 \\
\hline Phenylalanine (g/kg) & 6.6 & 2.4 \\
\hline Tyrosine (g/kg) & 6.9 & 2.4 \\
\hline Histidine (g/kg) & 3.4 & 1.4 \\
\hline Threonine $(\mathrm{g} / \mathrm{kg})$ & 9.7 & 3.3 \\
\hline Tryptophan (g/kg) & 3.4 & 1.0 \\
\hline Valine $(\mathrm{g} / \mathrm{kg})$ & 8.4 & 3.2 \\
\hline \multicolumn{3}{|l|}{ Formula (g/kg) } \\
\hline Corn & 430 & 430 \\
\hline Lactalbumin (Fonterra, NZ) & 177 & 35 \\
\hline DL-Methionine & 2.0 & 0.4 \\
\hline Corn starch & 149 & 287.4 \\
\hline Maltodextrin & 100 & 100 \\
\hline Corn oil & 29 & 32 \\
\hline Olive oil & 29 & 32 \\
\hline Cellulose & 30 & 30 \\
\hline *Mineral Mix, AIN-93G-MX & 35 & 35 \\
\hline Calcium phosphate & 8 & 8 \\
\hline **Vitamin Mix, Tekland & 10 & 10 \\
\hline
\end{tabular}

*Mineral Mix, AIN-93G-MX (No. 94046), ${ }^{* *}$ Vitamin Mix, Teklad (40060) 
more sustainable than the protein-free diets used in some recent studies. Interestingly, while intermittent fasting extends mouse lifespan, here we observed increased mTORC1 signaling in many tissues of intermittently fasted mice, suggesting that the lifespan extension observed following IF may be mTOR-independent. Future studies are warranted to determine if reduced mTORC1 signaling is the mechanism by which PR promotes health and longevity, to determine how PR impacts the circulating and tissue levels of amino acids and their metabolites, and to identify how factors such as protein quality and genetic background may influence the effect of a PR diet on mTOR signaling, longevity, and age-related diseases including cancer.

\section{MATERIALS AND METHODS}

Antibodies to phospho-Akt S473 (4060), Akt (4691), phospho-S6 S240/S244 (2215) and S6 ribosomal protein (2217) were from Cell Signaling Technology. Protease and phosphatase inhibitor cocktail tablets were from Fisher. Other chemicals were purchased from Sigma unless noted. 2.0 mL Tough Tubes with Caps (13119-500) and $1.4 \mathrm{mM}$ ceramic beads (13113-325), were purchased from Mo-Bio Laboratories, Carlsbad, CA.

\section{Animals}

Six week old, female NOD.Cg-Prkdc scid $I l 2 \mathrm{rg}^{\text {tm } 1 \mathrm{Wjl} /}$ SzJ mice were purchased from The Jackson Laboratory. Mice were housed and maintained in a sterile and pathogen free facility, in accordance with the Institutional guidelines of the Institutional Animal Care and Use Committee of the Washington University in St. Louis. WHIM16 tumor cell line was generated from a patient with ER positive/ PR negative/ HER2 negative breast cancer (Washington University). This tumor cell line carries also a PI3K mutation with activation of the AKT/mTOR pathway (manuscript submitted). Five million WHIM16 cells were implanted subcutaneously under the skin. All mice were operated under sedation with oxygen, isoflurane and buprenorphine. Mice were randomly grouped and placed on ad libitum or alternate day fasting $21 \%$ or $7 \%$ protein diets prior to tumor implantation ( $n=10$ per group).

\section{Feeding protocol}

The two experimental diets were prepared and sterilized by irradiation by Harlan Laboratories (Madison, WI). A summary of the composition and ingredients of each diet are shown in Table 1. Animals were allowed free access to autoclaved water supply via auto-watering system. Female mice that were randomized into $21 \%$ protein diet and $7 \%$ protein diet were further randomized within each group to either receive food ad libitum or every other day.

\section{Tumor assessment}

For tumors implanted subcutaneously, tumor sizes and body weights were recorded once a week. Tumor sizes were assessed by caliper measurements of two diameters of the tumor (longest length $\times$ shortest length $=\mathrm{mm}^{2}$ ). Tumor growth rate was calculated by summarizing the means and standard deviations for each group from 3-12 weeks following tumor cell implantation, and Laird and Ware's (1982) [34] growth curve method was used to compare the differences between groups. All the tests were two-sided and a $p$-value of 0.05 or less was taken to indicate statistical significance. The statistical analysis was performed using SAS 9.3 (SAS Institutes, Cary, NC).

\section{Tissue collection and immunoblotting}

At the end of the xenograft experiment, at the conclusion of a full day during which both the ad libitum and intermittently fed groups had access to food, the food was removed at 7:30 am and the mice were then euthanized. The xenograft tumors were excised and liver, heart and skeletal muscle, and adipose tissues were collected, frozen immediately in liquid nitrogen and stored at -80C. Tissue samples were lysed in cold RIPA buffer supplemented with phosphatase inhibitor and protease inhibitor cocktail tablets. Tissues were lysed in RIPA buffer as previously described [18] using a FastPrep 24 (M.P. Biomedicals) with bead-beating tubes and ceramic beads (Mo-Bio Laboratories), and then centrifuged for 10 minutes at $15,000 \mathrm{rpm}$. Protein concentration was determined by Bradford (Bio-Rad). $20 \mu \mathrm{g}$ protein was separated by sodium dodecylsulpahte-polyacrylamide gel electrophoresis (SDS-PAGE) on 10\% resolving gels (Life Technologies/ThermoFisher). Imaging was performed using a GE ImageQuant LAS 4000 imaging station. Quantification was performed by densitometry using ImageJ software. Statistical analysis was performed by one-way ANOVA followed by post-hoc tests using Prism (GraphPad Software).

\section{ACKNOWLEDGMENTS}

We would like to thank all the members of the Lamming and Fontana labs, as well as the Davis, Kimple and Merrins labs for the use of equipment and thoughtful discussion.

\section{FUNDING}

The Fontana lab is supported by grants from the Bakewell Foundation. The Lamming lab is supported in part by a grant from the National Institute of Health and startup funds from the UW-Madison School of Medicine and Public Health and the UW-Madison Department of Medicine. D.W.L is supported in part by a K99/R00 
Pathway to Independence Award from the NIH/NIA (AG041765). This work was supported using facilities and resources from the William S. Middleton Memorial Veterans Hospital. This work does not represent the views of the Department of Veterans Affairs or the United States Government.

\section{CONFLICTS OF INTEREST}

None of the authors had conflicts of interest.

\section{REFERENCES}

1. Solon-Biet SM, McMahon AC, Ballard JW, Ruohonen K, Wu LE, Cogger VC, Warren A, Huang X, Pichaud N, Melvin RG, Gokarn R, Khalil M, Turner N, Cooney GJ, Sinclair DA, Raubenheimer D, et al. The ratio of macronutrients, not caloric intake, dictates cardiometabolic health, aging, and longevity in ad libitum-fed mice. Cell Metab. 2014; 19:418-430.

2. Arum O, Bonkowski MS, Rocha JS, Bartke A. The growth hormone receptor gene-disrupted mouse fails to respond to an intermittent fasting diet. Aging Cell. 2009; 8:756-760.

3. Fontana L, Partridge L. Promoting health and longevity through diet: from model organisms to humans. Cell. 2015; 161:106-118.

4. Mattson MP, Allison DB, Fontana L, Harvie M, Longo VD, Malaisse WJ, Mosley M, Notterpek L, Ravussin E, Scheer FA, Seyfried TN, Varady KA, Panda S. Meal frequency and timing in health and disease. Proc Natl Acad Sci U S A. 2014; 111:16647-16653.

5. Levine ME, Suarez JA, Brandhorst S, Balasubramanian P, Cheng CW, Madia F, Fontana L, Mirisola MG, GuevaraAguirre J, Wan J, Passarino G, Kennedy BK, Wei M, Cohen P, Crimmins EM, Longo VD. Low protein intake is associated with a major reduction in IGF-1, cancer, and overall mortality in the 65 and younger but not older population. Cell Metab. 2014; 19:407-417.

6. Parrella E, Maxim T, Maialetti F, Zhang L, Wan J, Wei M, Cohen P, Fontana L, Longo VD. Protein restriction cycles reduce IGF-1 and phosphorylated Tau, and improve behavioral performance in an Alzheimer's disease mouse model. Aging Cell. 2013; 12:257-268.

7. Fontana L, Adelaiye RM, Rastelli AL, Miles KM, Ciamporcero E, Longo VD, Nguyen H, Vessella R, Pili R. Dietary protein restriction inhibits tumor growth in human xenograft models. Oncotarget. 2013; 4:2451-2461.

8. Tajes M, Gutierrez-Cuesta J, Folch J, Ortuno-Sahagun D, Verdaguer E, Jimenez A, Junyent F, Lau A, Camins A, Pallas M. Neuroprotective role of intermittent fasting in senescence-accelerated mice P8 (SAMP8). Exp Gerontol. 2010; 45:702-710.

9. Fontana L, Weiss EP, Villareal DT, Klein S, Holloszy JO. Long-term effects of calorie or protein restriction on serum
IGF-1 and IGFBP-3 concentration in humans. Aging Cell. 2008; 7:681-687.

10. Thissen JP, Ketelslegers JM, Underwood LE. Nutritional regulation of the insulin-like growth factors. Endocr Rev. 1994; 15:80-101.

11. Lamming DW. Diminished mTOR signaling: a common mode of action for endocrine longevity factors. SpringerPlus. 2014; 3:735.

12. Anisimov VN, Zabezhinski MA, Popovich IG, Piskunova TS, Semenchenko AV, Tyndyk ML, Yurova MN, Antoch MP, Blagosklonny MV. Rapamycin extends maximal lifespan in cancer-prone mice. Am J Pathol. 2010; 176:2092-2097.

13. Blagosklonny MV. Once again on rapamycin-induced insulin resistance and longevity: despite of or owing to. Aging (Albany NY). 2012; 4:350-358.

14. Harrison DE, Strong R, Sharp ZD, Nelson JF, Astle CM, Flurkey K, Nadon NL, Wilkinson JE, Frenkel K, Carter CS, Pahor M, Javors MA, Fernandez E, Miller RA. Rapamycin fed late in life extends lifespan in genetically heterogeneous mice. Nature. 2009; 460:392-395.

15. Trelinska J, Dachowska I, Kotulska K, Fendler W, Jozwiak S, Mlynarski W. Complications of mammalian target of rapamycin inhibitor anticancer treatment among patients with tuberous sclerosis complex are common and occasionally life-threatening. Anti-cancer drugs. 2015; 26:437-442.

16. Lamming DW, Ye L, Sabatini DM, Baur JA. Rapalogs and mTOR inhibitors as anti-aging therapeutics. J Clin Invest. $2013 ; 123: 980-989$.

17. Lamming DW, Mihaylova MM, Katajisto P, Baar EL, Yilmaz OH, Hutchins A, Gultekin Y, Gaither R, Sabatini DM. Depletion of Rictor, an essential protein component of mTORC2, decreases male lifespan. Aging Cell. 2014; 13:911-917.

18. Lamming DW, Ye L, Katajisto P, Goncalves MD, Saitoh M, Stevens DM, Davis JG, Salmon AB, Richardson A, Ahima RS, Guertin DA, Sabatini DM, Baur JA. Rapamycin-induced insulin resistance is mediated by mTORC2 loss and uncoupled from longevity. Science. 2012; 335:1638-1643.

19. Schreiber KH, Ortiz D, Academia EC, Anies AC, Liao CY, Kennedy BK. Rapamycin-mediated mTORC2 inhibition is determined by the relative expression of FK506-binding proteins. Aging Cell. 2015; 14:265-273.

20. Harputlugil E, Hine C, Vargas D, Robertson L, Manning BD, Mitchell JR. The TSC complex is required for the benefits of dietary protein restriction on stress resistance in vivo. Cell reports. 2014; 8:1160-1170.

21. Grabiner BC, Nardi V, Birsoy K, Possemato R, Shen K, Sinha S, Jordan A, Beck AH, Sabatini DM. A diverse array of cancer-associated MTOR mutations are hyperactivating and can predict rapamycin sensitivity. Cancer discovery. 2014; 4:554-563. 
22. Bar-Peled L, Chantranupong L, Cherniack AD, Chen WW, Ottina KA, Grabiner BC, Spear ED, Carter SL, Meyerson M, Sabatini DM. A Tumor suppressor complex with GAP activity for the Rag GTPases that signal amino acid sufficiency to mTORC1. Science. 2013; 340:1100-1106.

23. Kwiatkowski DJ, Zhang H, Bandura JL, Heiberger KM, Glogauer M, el-Hashemite N, Onda H. A mouse model of TSC1 reveals sex-dependent lethality from liver hemangiomas, and up-regulation of p70S6 kinase activity in Tsc1 null cells. Hum Mol Genet. 2002; 11:525-534.

24. Bhasin KK, van Nas A, Martin LJ, Davis RC, Devaskar SU, Lusis AJ. Maternal low-protein diet or hypercholesterolemia reduces circulating essential amino acids and leads to intrauterine growth restriction. Diabetes. 2009; 58:559-566.

25. Chantranupong L, Wolfson RL, Sabatini DM. Nutrientsensing mechanisms across evolution. Cell. 2015; 161:67-83.

26. Jastrzebski K, Hannan KM, Tchoubrieva EB, Hannan RD, Pearson RB. Coordinate regulation of ribosome biogenesis and function by the ribosomal protein S6 kinase, a key mediator of mTOR function. Growth Factors. 2007; 25:209-226.

27. Thoreen CC, Chantranupong L, Keys HR, Wang T, Gray NS, Sabatini DM. A unifying model for mTORC1mediated regulation of mRNA translation. Nature. 2012; 485:109-113.

28. Thoreen CC, Kang SA, Chang JW, Liu Q, Zhang J, Gao Y, Reichling LJ, Sim T, Sabatini DM, Gray NS.
An ATP-competitive mammalian target of rapamycin inhibitor reveals rapamycin-resistant functions of mTORC1. J Biol Chem. 2009; 284:8023-8032.

29. Guertin DA, Stevens DM, Saitoh M, Kinkel S, Crosby K, Sheen JH, Mullholland DJ, Magnuson MA, Wu H, Sabatini DM. mTOR complex 2 is required for the development of prostate cancer induced by Pten loss in mice. Cancer Cell. 2009; 15:148-159.

30. Moschetta M, Reale A, Marasco C, Vacca A, Carratu MR. Therapeutic targeting of the mTOR-signalling pathway in cancer: benefits and limitations. British journal of pharmacology. 2014; 171:3801-3813.

31. Powell JD, Pollizzi KN, Heikamp EB, Horton MR. Regulation of immune responses by mTOR. Annual review of immunology. 2012; 30:39-68.

32. Lamming DW, Demirkan G, Boylan JM, Mihaylova MM, Peng T, Ferreira J, Neretti N, Salomon A, Sabatini DM, Gruppuso PA. Hepatic signaling by the mechanistic target of rapamycin complex 2 (mTORC2). FASEB J. 2014; 28:300-315.

33. Kumar A, Harris TE, Keller SR, Choi KM, Magnuson MA, Lawrence JC Jr. Muscle-specific deletion of rictor impairs insulin-stimulated glucose transport and enhances Basal glycogen synthase activity. Mol Cell Biol. 2008; 28:61-70.

34. Laird NM, Ware JH. Random-effects models for longitudinal data. Biometrics. 1982; 38:963-974. 